\title{
Left ventricular volume measured rapidly by oblique magnetic resonance imaging
}

\author{
S R UNDERWOOD, C R W GILL, * D N FIRMIN, R H KLIPSTEIN, \\ R H MOHIADDIN, R S O REES, D B LONGMORE
}

From the National Heart and Chest Hospitals, and ${ }^{*}$ The Bank of England, London

SUMMARY Magnetic resonance measurements of left ventricular volume and ejection fraction based on measurements of area and length in a single oblique plane containing the long axis of the ventricle were compared with measurements made by summing the areas of the chamber in multiple contiguous slices. The multislice technique is known to be accurate, but the single slice technique is much quicker; it takes only nine minutes of acquisition time for both volume and ejection fraction. In 25 normal subjects there was good agreement between the two methods of measuring volume with a mean (SD) difference between measurements of $2.0(6.6) \mathrm{ml}$. In 20 patients with previous infarction it was less good with a mean (SD) difference of $4 \cdot 5(18 \cdot 1) \mathrm{ml}$. The mean (SD) difference of ejection fraction measurements was $-0.019(0.038)$ in the normal subjects and $-0.059(0 \cdot 106)$ in the patients, and the discrepancy between the two techniques was greatest in the patients with a pronounced abnormality of wall motion and low ejection fraction. In a further 25 normal subjects, the agreement between single plane volume measurements in the vertical and horizontal long axis planes was good, indicating that either plane is suitable for rapid measurement.

Single plane measurements of left ventricular volume and ejection fraction can be made with the accuracies stated, which are sufficient for routine clinical use except in patients with a pronounced abnormality of wall motion. In combination with measurements of regional wall thickness and motion, previously described, the technique offers a rapid non-invasive assessment of both global and regional left ventricular function.

Left ventricular volume and ejection fraction are widely used as measures of global function. We have previously shown that magnetic resonance imaging provides an accurate method of measuring volume by summing the areas of the ventricle in contiguous transverse slices, ${ }^{1}$ and that these measurements have clinical value in the determination of global ventricular function and regurgitant fraction. ${ }^{2}$ Eight acquisitions are usually required to cover the whole left ventricle, however, and this may take up to $\mathbf{4 0}$ minutes, depending upon heart rate. Because images can now be acquired in oblique planes, more rapid measurements can be made from images containing the long axis of the left ventricle if the ventricle is assumed to be an ellipsoid of revolution about the long axis. Volume can then be calculated from a

Requests for reprints to Dr S R Underwood, Magnetic Resonance Unit, The National Heart and Chest Hospitals, 30 Britten Street, London SW3 6NN.

Accepted for publication 12 January 1988 single image and ejection fraction from a pair of images at end diastole and end systole.

To assess the validity of the rapid technique for routine use we compared measurements of left ventricular volume and ejection fraction from oblique images with those made by the multislice technique.

\section{Patients and methods}

We studied 50 symptom free volunteers without a history of cardiac disease (mean age 42, range 25-64), subsequently referred to as "normal subjects" because they were assumed to have normal left ventricular function. We also studied 20 patients with previous myocardial infarction (mean age 51 , range 40-73), which was established on the basis of the history and the electrocardiogram in conjunction with regional abnormalities of left ventricular contraction seen by either right anterior oblique $x$ ray contrast ventriculography or left anterior oblique 


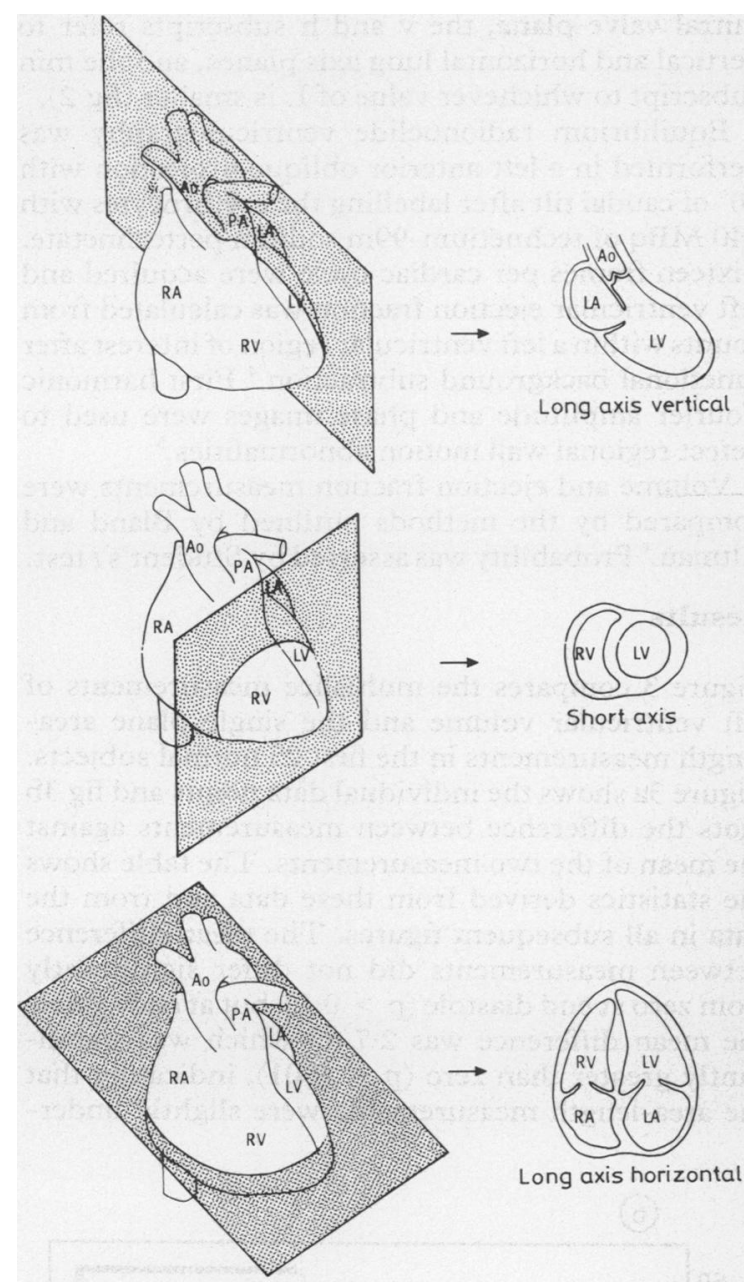

Fig 1 The vertical and horizontal long axis planes contain the long axis of the left ventricle and are roughly equivalent to the right anterior oblique view in $x$ ray contrast ventriculography and the apical four chamber view of echocardiography respectively.

equilibrium radionuclide ventriculography. The site of infarction was judged from the ventriculograms and there were abnormalities of the anterior wall in 14 patients, the septum in six, the inferior wall in nine, the lateral wall in two, and the apex in nine.

In the patients with previous infarction and in 25 of the normal subjects, volumes were measured by magnetic resonance by both the multislice method and a single plane area-length method in the horizontal long axis plane (fig 1). Radionuclide ventriculography was performed only in the patients and the radionuclide left ventricular ejection fraction was compared with the multislice magnetic resonance technique. The other 25 normal subjects were studied at a later date, when software improvements allowed both vertical and horizontal long axis planes to be imaged. In these subjects, we compared single plane area-length measurements in the horizontal and the vertical long axis planes and biplane measurements in which both planes were used.

We used a Picker International Vista MR2055 scanner operating at 0.5 tesla and an electrocardiographically gated spin echo sequence with an echo time of $40 \mathrm{~ms}$. Each acquisition consisted of two averages of 128 phase encoding steps; the pixel size was $1.17 \mathrm{~mm} \times 1.17 \mathrm{~mm}$ and the slice thickness was $10 \mathrm{~mm}$. In the initial study of 25 normal subjects and 20 patients with infarcts, measurements were made in the horizontal long axis plane, and the angle of depression of the long axis was determined from an initial sagittal image through the body of the left ventricle. In this plane, contiguous slices were acquired at end diastole and end systole to cover the whole left ventricle and the images were acquired in

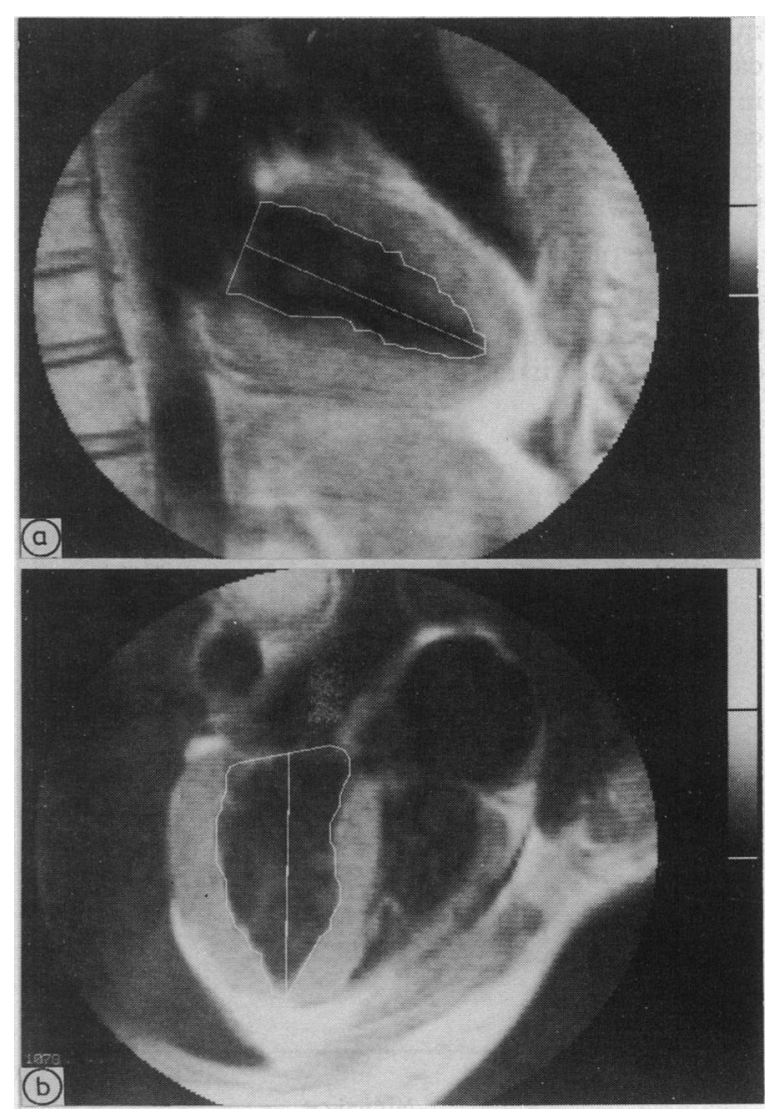

Fig 2 The area and length of the left ventricle in vertical (a) and horizontal long axis planes (b) were measured by tracing on the computer screen. The images displayed are of a normal subject with an end diastolic volume of $125 \mathrm{ml}$. 
pairs-diastole at one level and systole in another. The end systolic image was timed to coincide with the end of the electrocardiographic $T$ wave. Total acquisition time was approximately 30 minutes depending upon heart rate, but if the horizontal long axis images alone had been acquired it would have been five minutes for a single volume measurement or nine minutes for an ejection fraction measurement.

In the subsequent study of a further 25 normal subjects, the horizontal and vertical long axis planes were used (fig 2). An initial transverse image was acquired through the body of the left ventricle, and from this, the rotation of the ventricle towards the left could be seen. The vertical long axis images were acquired perpendicularly to the transverse plane but they were rotated to include the long axis of the ventricle. The depression of the ventricle was seen from the vertical long axis image and this permitted the horizontal long axis plane to be acquired.

Left ventricular endocardial contours were drawn manually on the computer screen and volume was calculated either by summing the area of the contour in each image (multislice technique) or from the central images containing the long axis of the ventricle (area-length technique). The following formulas were used for the area-length calculations ${ }^{3}$ :

$$
\begin{array}{ll}
\text { Single plane } & V=\left(8 \times A^{2}\right) /(3 \pi \times L) \\
\text { Biplane } & V=\left(8 \times A_{v} \times A_{h}\right) /\left(3 \pi \times L_{\text {min }}\right)
\end{array}
$$

where $A$ represents the area of the left ventricular cavity, $L$ the distance from apical endocardium to mitral valve plane, the $\mathrm{v}$ and $\mathrm{h}$ subscripts refer to vertical and horizontal lung axis planes, and the min subscript to whichever value of $\mathrm{L}$ is smaller (fig 2 ).

Equilibrium radionuclide ventriculography was performed in a left anterior oblique projection with $30^{\circ}$ of caudal tilt after labelling the erythrocytes with $740 \mathrm{MBq}$ of technetium-99m sodium pertechnetate. Sixteen frames per cardiac cycle were acquired and left ventricular ejection fraction was calculated from counts within a left ventricular region of interest after functional background subtraction. ${ }^{4}$ First harmonic Fourier amplitude and phase images were used to detect regional wall motion abnormalities. ${ }^{5}$

Volume and ejection fraction measurements were compared by the methods outlined by Bland and Altman. ${ }^{6}$ Probability was assessed by Student's $t$ test.

\section{Results}

Figure 3 compares the multislice measurements of $\vec{c}$ left ventricular volume and the single plane area- $\frac{\mathbb{}}{0}$ length measurements in the first 25 normal subjects. Figure $3 a$ shows the individual data points and fig $3 \mathrm{~b}$ plots the difference between measurements against the mean of the two measurements. The table shows the statistics derived from these data and from the data in all subsequent figures. The mean difference between measurements did not differ significantly from zero at end diastole ( $p>0 \cdot 1)$, but at end systole the mean difference was $2 \cdot 7 \mathrm{ml}$ which was significantly greater than zero $(p<0.01)$, indicating that the area-length measurements were slightly under-
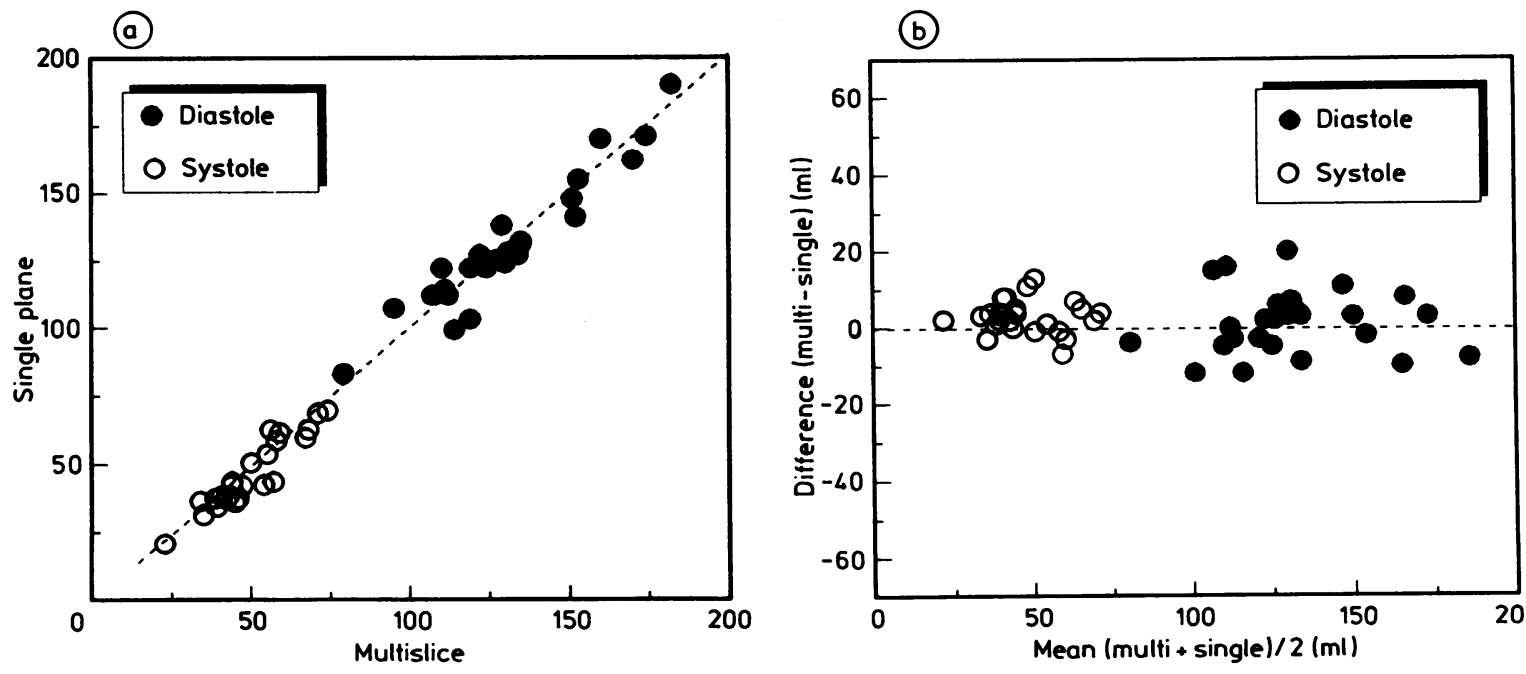

Fig 3 (a) Individual data points for single plane area-length measurements of left ventricular volume and multislice measurements in 25 normal subjects. The dotted line is the line of identity. (b) Difference between measurements plotted against the mean of each pair of measurements. 
Table Data derived from single and multislice magnetic resonance imaging

\begin{tabular}{|c|c|c|c|c|c|c|c|}
\hline Comparison & Subjects & No & Mean & Mean diff & $S D$ diff & Error & $p$ \\
\hline $\begin{array}{l}\text { Single } v \text { multi volume }(\mathrm{ml}) \\
\text { Diastole } \\
\text { Systole } \\
\text { Combined }\end{array}$ & Normal & $\begin{array}{l}25 \\
25 \\
50\end{array}$ & $\begin{array}{r}131 \\
51 \\
92\end{array}$ & $\begin{array}{l}1 \cdot 3 \\
2 \cdot 7 \\
2 \cdot 0\end{array}$ & $\begin{array}{l}8 \cdot 2 \\
4 \cdot 5 \\
6 \cdot 7\end{array}$ & $\begin{array}{l}6 \cdot 2 \% \\
8 \cdot 8 \% \\
7 \cdot 3 \%\end{array}$ & $\begin{array}{l}\text { NS } \\
<0.01 \\
<0.05\end{array}$ \\
\hline $\begin{array}{l}\text { Single } v \text { multi volume }(\mathrm{ml}) \\
\text { Diastole } \\
\text { Systole } \\
\text { Combined } \\
\text { Single } v \text { multi EF } \\
\text { Single } v \text { multi EF } \\
\text { Single (VLA) } v \text { biplane (ml) } \\
\text { Single (HLA) } v \text { biplane (ml) } \\
\text { Single (VLA) } v \text { single (HLA) } \\
\text { Radionuclide } v \text { multi EF }\end{array}$ & $\begin{array}{l}\text { Normal } \\
\text { Infarct } \\
\text { Normal } \\
\text { Normal } \\
\text { Normal } \\
\text { Infarct }\end{array}$ & $\begin{array}{l}20 \\
20 \\
40 \\
25 \\
20 \\
50 \\
50 \\
50 \\
20\end{array}$ & $\begin{array}{c}187 \\
114 \\
150 \\
0.62 \\
0.41 \\
87 \\
87 \\
90 \\
0.41\end{array}$ & $\begin{array}{c}-1 \cdot 1 \\
10 \cdot 1 \\
4.5 \\
-0.019 \\
-0.059 \\
-2.2 \\
-5.0 \\
2.8 \\
0.026\end{array}$ & $\begin{array}{l}17 \cdot 8 \\
18.4 \\
19.0 \\
0 \cdot 038 \\
0 \cdot 106 \\
12 \cdot 2 \\
12 \cdot 2 \\
23.1 \\
0.052\end{array}$ & $\begin{array}{r}9.6 \% \\
16 \cdot 1 \% \\
12 \cdot 6 \% \\
6 \cdot 2 \% \\
25 \cdot 7 \% \\
14 \cdot 1 \% \\
14 \cdot 1 \% \\
25 \cdot 6 \% \\
12.5 \%\end{array}$ & $\begin{array}{l}\text { NS } \\
<0.01 \\
\text { NS } \\
<0.01 \\
<0.01 \\
<0.05 \\
<0.05 \\
\text { NS } \\
<0.001\end{array}$ \\
\hline
\end{tabular}

No, number of measurements; mean, mean of the measurements; mean diff, mean difference between measurements (the second minus the first); SD diff, standard deviation of the difference between measurements; error, SD diff $\div$ mean; single, single plane area length measurement; biplane, biplane area length measurement; multi, multislice measurement; VLA, vertical long axis; HLA, horizontal long axis; EF, ejection fraction.

estimated. The standard deviation of the difference between measurements (SD diff) and the percentage error $((\mathrm{SD}$ diff $) /$ mean) were sufficiently low $(8 \cdot 2 \mathrm{ml}$ $(6 \cdot 2 \%)$ diastole, $4.5 \mathrm{ml}(8 \cdot 8 \%)$ systole) for the arealength measurements to be clinically useful in normal subjects.

Figure 4 compares the volume measurements in the 20 patients with previous infarction. As in the normal subjects, the mean difference between measurements did not differ significantly from zero at end diastole ( $p>0.5$ ), but at end systole the arealength technique gave a slight underestimate of volume (mean difference $10.1 \mathrm{ml}, \mathrm{p}<0.05$ ). The standard deviation of the difference between measurements and the percentage error, however, were much higher than in the normal subjects $(17.8 \mathrm{ml}(9.6 \%)$ diastole, $18.4 \mathrm{ml}(16.1 \%)$ systole). There was no obvious difference between those with anterior or septal infarction and those with inferior infarction. Figure 5 shows the systolic horizontal long axis image of a patient with anterolateral infarction and apical dyskinesia. The shape of the left ventricle was irregular compared with the normal subject in fig 2 and there is thinning of the lateral wall with considerable thinning at the apex. The multislice measurements of diastolic and systolic volume were $195 \mathrm{ml}$ and $125 \mathrm{ml}$, giving an ejection fraction of 0.37 , and the area-length volumes were $180 \mathrm{ml}$ and
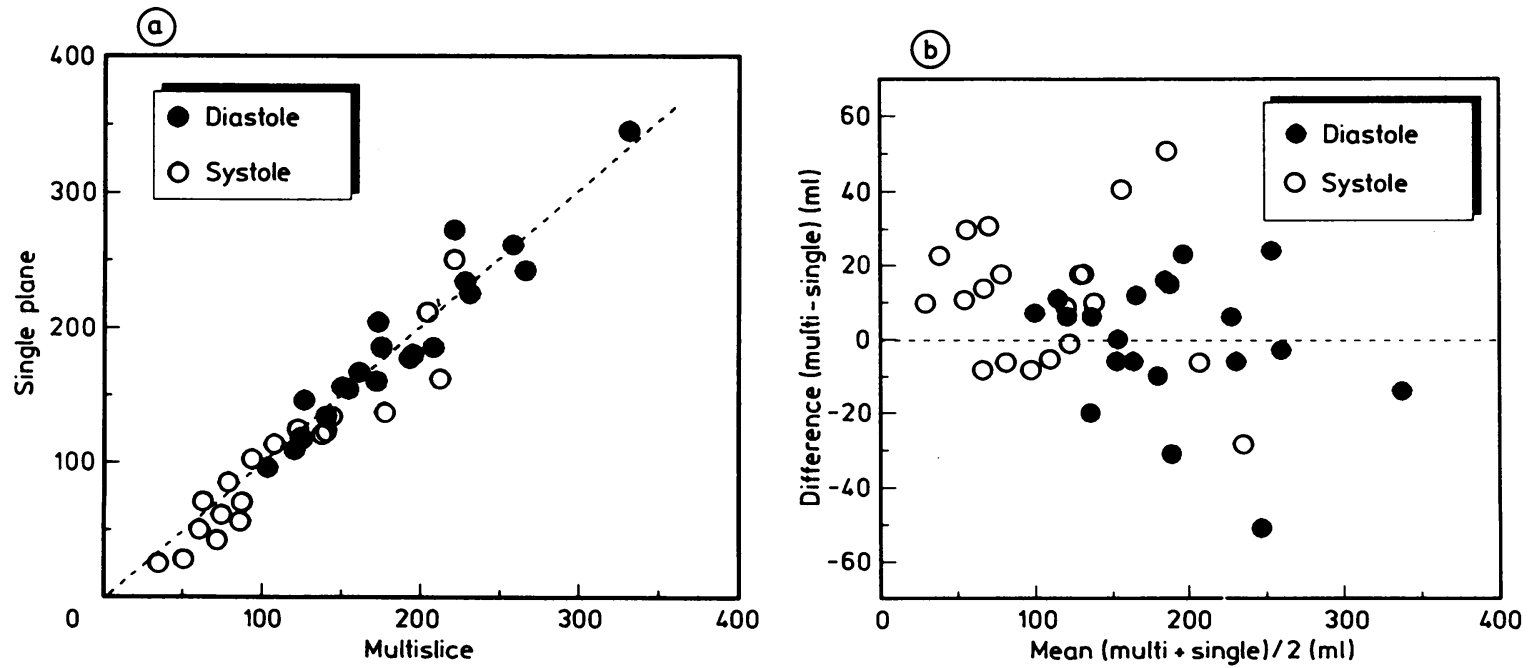

Fig 4 Individual data points for single plane area-length measurements of left ventricular volume and multislice measurements in 20 patients with previous infarction. The dotted line is the line of identity. (b) Difference between measurements plotted against the mean of each pair of measurements. 


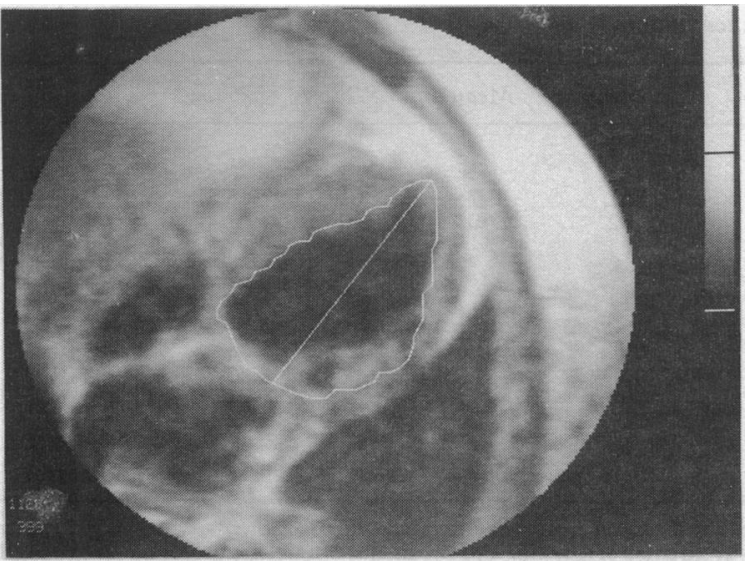

Fig 5 Systolic horizontal long axis image of a patient with previous anterolateral and apical infarction. There is thinning of the lateral wall and apex, and there is intracavitary signal from static blood close to the basal lateral wall. The area of the left ventricular cavity and its long axis are indicated.

$117 \mathrm{ml}$, giving an ejection fraction of 0.35 .

Figure 6 compares the ejection fractions calculated from the diastolic and systolic multislice and single plane volumes in the normal subjects and in the patients. In both cases, the mean difference between measurements was significantly less than zero ( $p<$ 0.01 ), indicating that the area-length technique overestimated the ejection fraction. The standard deviation of the difference and percentage error were much smaller in the normal subjects $(0.038,6.2 \%) \stackrel{\frac{a}{c}}{c}$ than in the patients with infarcts $(0 \cdot 106,25 \cdot 7 \%), \stackrel{.}{\Rightarrow}$ indicating that in normal ventricles the area-length $\stackrel{0}{\rightarrow}$ technique may lead to errors of up to 0.07 in ejection $\bar{c}$ fraction, but in abnormal ventricles these errors may $\underline{\bar{D}}$ be as high as $\mathbf{0} \cdot \mathbf{2 1}$. Inspection of the data shows that $\frac{\bar{\omega}}{\vec{\sigma}}$ much of this error arose in three patients with $\stackrel{\mathbb{Q}}{\AA}$ ejection fractions of approximately 0.20 by the multislice technique, and these were all patients with pronounced wall motion abnormalities.

Figure 7 compares the radionuclide ejection fraction measurements in the patients with those made by magnetic resonance with the multislice technique. Although radionuclide ventriculography under- os estimated the ejection fraction by a mean of 0.026 ( $p \dot{\omega}$ $<0.01$ ), the standard deviation of the difference $\vec{\infty}$ between measurements was 0.052 which is probably $\infty$ low enough for routine clinical use of the radionu- $\frac{\rho}{3}$ clide technique.

Figure 8 compares the single plane volume $\mathscr{D}$ measurements in vertical and horizontal long axis $\underset{\vec{D}}{\mathrm{~T}}$ planes in the second group of normal subjects. At end systole the mean (SD) difference between measurements (horizontal long axis - vertical long axis) was $6.1(15.0) \mathrm{ml}$ which was significantly different from zero $(p<0.05)$. At end diastole, the mean (SD) difference $(-0.6(29.3) \mathrm{ml})$ was not significantly different from zero $(p>0.05)$, although a single spurious point probably affected this result. These differences are sufficiently small for either plane to be suitable for measurement of ventricular volume.

\section{(a)}

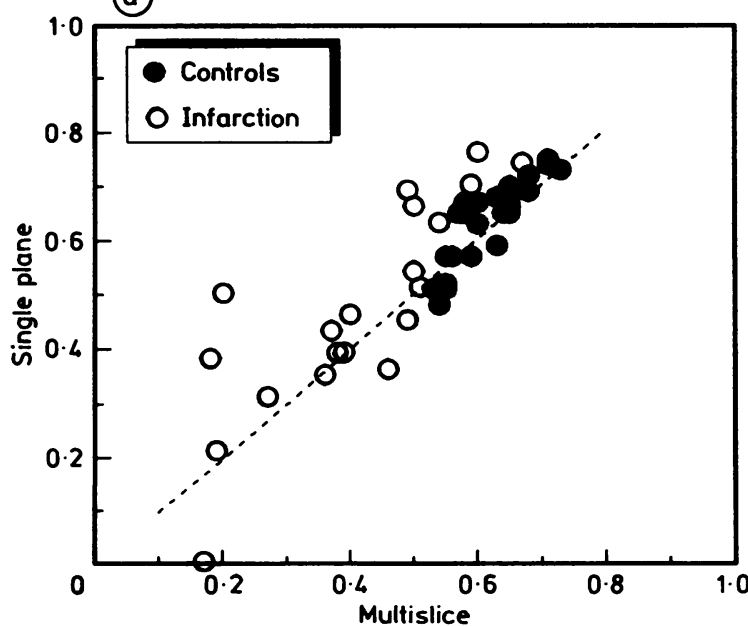

(b)

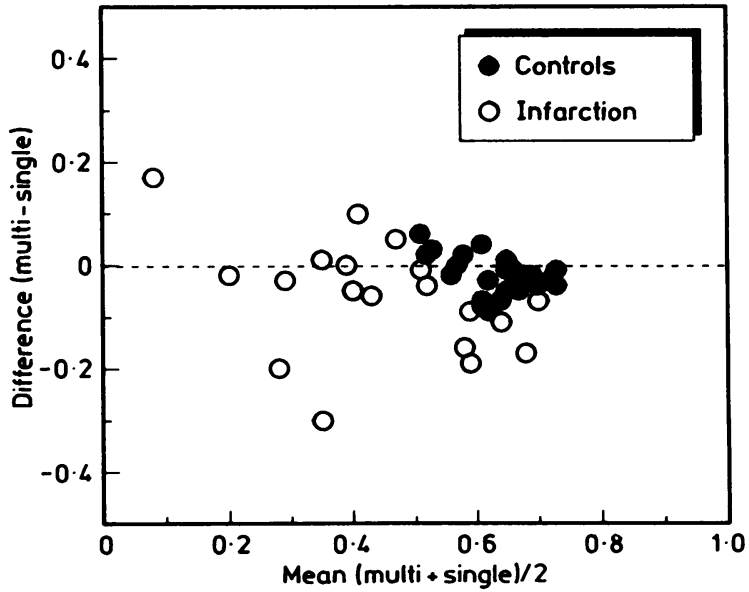

Fig 6 (a) Individual data points for single plane area-length measurements of left ventricular ejection fraction and multislice measurements in 25 normal subjects and 20 patients with previous infarction. The dotted line is the line of identity. (b) Difference between measurements plotted against the mean of each pair of measurements. 
(a)

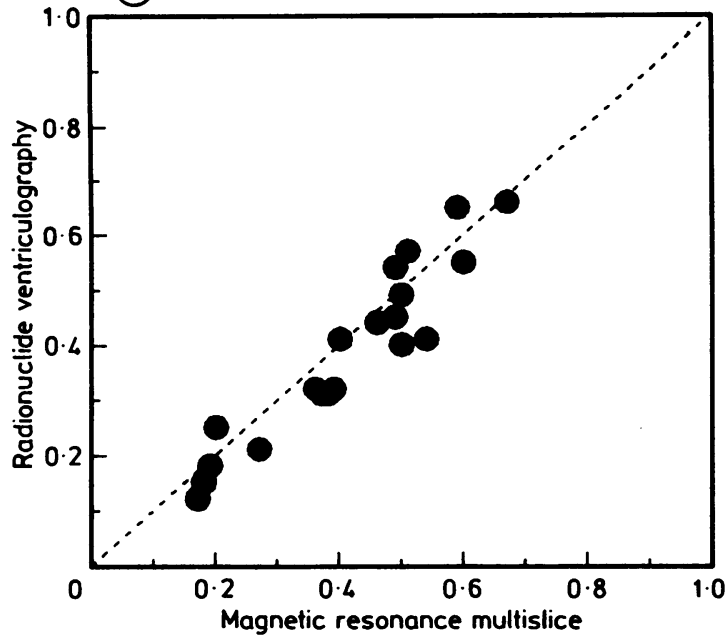

(b)

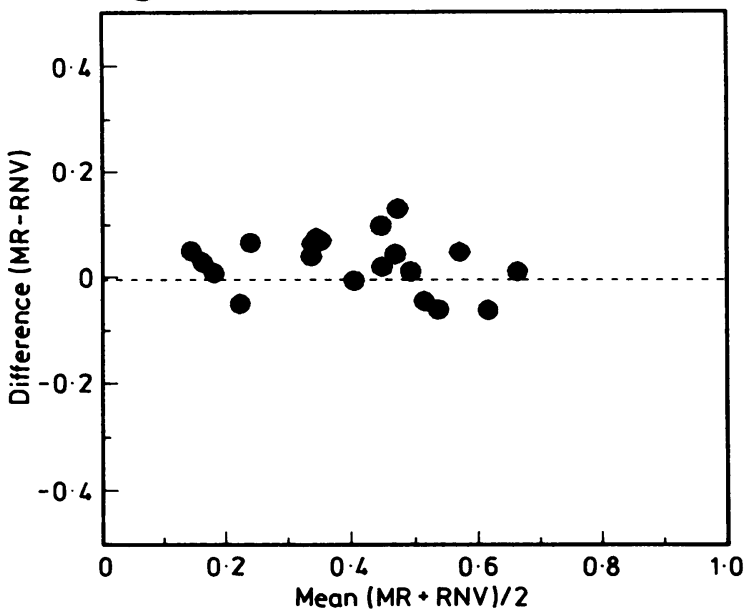

Fig 7 (a) Individual data points for left ventricular ejection fraction measured by radionuclide ventriculography and by the multislice magnetic resonance technique. The dotted line is the line of identity. (b) Difference between measurements plotted against the mean of each pair of measurements.

\section{Discussion}

The importance of measuring left ventricular volume is highlighted by its long history. ${ }^{7}$ Invasive techniques based on $x$ ray contrast ventriculography have been used for many years, and they assume that the left ventricle is either an ellipsoid or a prolate spheroid. The method first proposed by Chapman et $\mathrm{al}^{8}$ is similar to the multislice technique used in this study in that the areas of sections through the left ventricle are summed. The method was too tedious for routine use and it was eclipsed by the methods of Arvidsson ${ }^{9}$ and Dodge $e t a^{10}$ in which the minor axes of the ellipsoid are either measured directly or are calculated from the projected area of the left ventricle. Adaptation of the technique for single plane ventriculograms ${ }^{112}$ and for oblique biplane ventriculograms ${ }^{3}$ has been successful, and the subject has

(a)

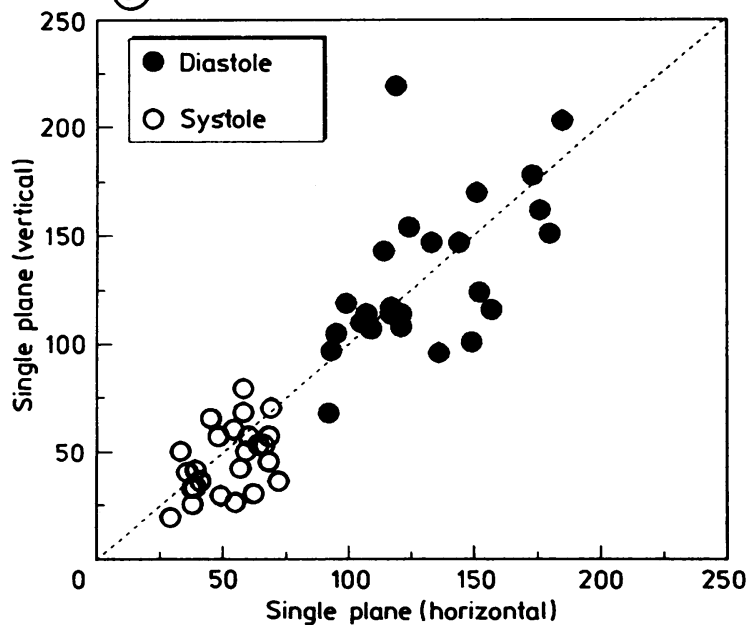

(b)

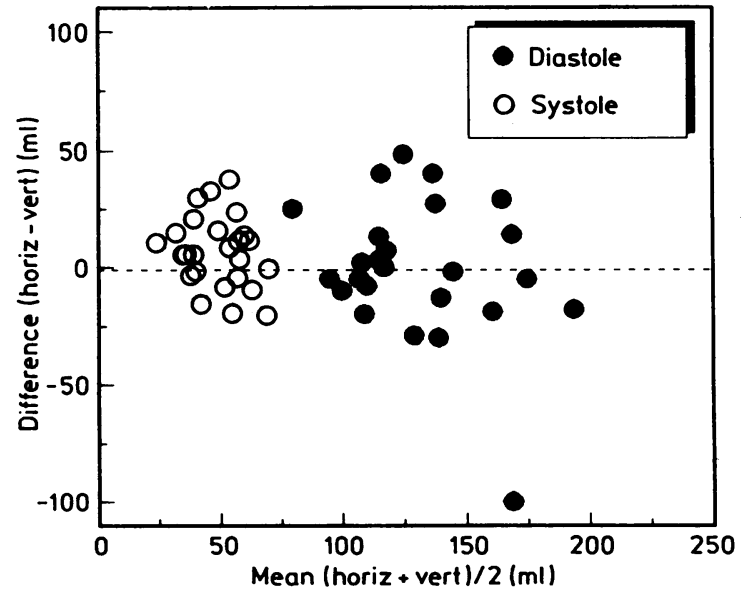

Fig 8 (a) Individual data points for single plane volume measurements in the vertical and horizontal long axis planes in 25 normal subjects. The dotted line is the line of identity. (b) Difference between measurements plotted against the mean of each pair of measurements. 
been well reviewed. ${ }^{1314}$ Both the multislice and the area-length methods used in this study have been extensively studied but their application to magnetic resonance imaging is newer.

Previous studies have investigated magnetic resonance imaging for the determination of left ventricular volume and various techniques have been used. The multislice method is the most accurate because it makes few assumptions about ventricular geometry and it has been validated by a comparison of left and right ventricular stroke volumes in normal subjects. ${ }^{15}$ Although there are some sources of error, such as the partial volume effect and ambiguities in defining the endocardium, it is probably the most accurate non-invasive method of measuring left ventricular volume, and it is a suitable standard against which to judge other techniques. It has also been compared with biplane $x$ ray cineangiography ${ }^{16}$ and with measurements of cardiac output from indicator dilution ${ }^{17}$ and thermodilution, ${ }^{18}$ but the invasive nature of these techniques makes them a less suitable comparison. Single plane ${ }^{19-21}$ and biplane $e^{22}$ area-length measurements have also been reported and have been compared with $x$ ray angiography, but there are no reports of a comparison of area-length with multislice measurements.

We have shown that single plane area-length measurements of left ventricular volume agree well with multislice measurements in normal subjects with a mean error throughout the range of volumes of $7 \cdot 3 \%$, which is adequate for routine clinical use. The mean error is less at end diastole $(6.2 \%)$ than at end systole $(8.8 \%)$, suggesting that the ventricle more closely fits the assumed geometry at end diastole. In patients with infarcts the agreement is less good, presumably because of the abnormally shaped ventricle. The mean error throughout the range of volumes is $12.6 \%$, and it is much higher at end systole $(16 \cdot 1 \%)$ than at end diastole $(9 \cdot 6 \%)$. This is consistent with the assumption that the abnormal ventricle deviates most from an ellipsoid of revolution at end systole. We expected that the correlation would be worst in inferior infarction because the horizontal long axis plane does not include the inferior wall, and errors would be greatest in these patients. No consistent difference was seen between inferior and septal infarction, however, but this may have been because the number of patients was small. In addition, there were few patients in whom the infarct was limited to a single region.

The mean error in ejection fraction measured by the area-length method was also much greater in the abnormal ventricles than in the normal ventricles. The error of $6.2 \%$ is adequate for clinical use in normal ventricles, but the error of $25.7 \%$ in abnormal ventricles indicates that the single plane measurements should not be used in patients with $\stackrel{\frac{\varrho}{c}}{c}$ previous infarcts.

The comparison of vertical and horizontal long $\underset{\vec{\rho}}{\vec{\rho}}$ axis volume measurements (fig 8) showed that $\overrightarrow{0}$ volumes were slightly higher in the horizontal long $\frac{0}{\sigma}$ axis plane, but the mean difference across the range of $\frac{\bar{c}}{\frac{\mathrm{c}}{\mathrm{a}}}$ volumes was only $2.8 \mathrm{ml}$. This indicates that in practice both planes are equivalent, but the vertical long axis plane is more familiar to the cardiologist since it is similar to the right anterior oblique ventriculogram. It also requires only a single pilot $\overrightarrow{\vec{\omega}}$ image to identify the plane and so permits more rapid imaging.

Apart from the assumptions of ventricular geometry, the single plane and biplane techniques for measuring volume make other assumptions that may not always be warranted. The oblique planes were $\infty$ identified at end systole and the same planes were $\frac{\circ}{3}$ used for the end diastolic images. If the long axis of the ventricle moves between the two, then the end $\infty$ diastolic images may not contain the true long axis. In fact, it is possible to display on an image the line along which any other image cuts it, and hence check that the true long axis is included at end diastole. Separate planes could have been identified for dias- $\vec{\varnothing}$ tole and systole, but this would have lengthened the acquisition time by a further two pilot scans and we did not think that this was necessary for routine measurements.

A further problem in any technique requiring identification of the endocardial surface is the $\mathbb{D}$ accuracy with which the boundary can be traced. We have previously discussed the problems of edge detection, ${ }^{2}$ but the principal problem in this study was the distinction between myocardium and slowly moving blood within the left ventricular cavity. This problem is apparent in fig 5 , but with experience slowly moving blood can usually be distinguished by its high and non-uniform signal. In cases of doubt, a field even echo rephasing sequence can be used. ${ }^{23}$ This sequence gives high signal from all non-turbulent blood and low signal from myocardium, and it aids the definition of the endocardial boundary and 9 the distinction of slowly moving blood from thrombus. ${ }^{24}$

\section{Conclusion}

Single plane area-length measurements of left $\mathrm{W}$ ventricular volume agree well with multislice measurements, which are of proven accuracy, and the agreement is slightly better at end diastole than at end systole in normal ventricles. In patients with previous infarction, the agreement is less good. Ejection fractions calculated from single plane volumes are sufficiently accurate for routine use in 
normal ventricles but they should be interpreted with caution in patients with abnormal ventricles. Both the vertical and horizontal long axis planes can be used, but if time is limited the vertical long axis images can be acquired slightly more quickly. In combination with regional wall motion studies from the same images, ${ }^{25}$ both global and regional left ventricular function can be assessed in a short time by magnetic resonance imaging.

\section{References}

1 Longmore DB, Klipstein RH, Underwood SR, et al. Dimensional accuracy of magnetic resonance in studies of the heart. Lancet 1985;i:1360-2.

2 Underwood SR, Klipstein RH, Firmin DN, et al. Magnetic resonance assessment of aortic and mitral regurgitation. Br Heart $J$ 1986;56:455-62.

3 Wynne J, Green LH, Mann T, Levin D, Grossman W. Estimation of left ventricular volumes in man from biplane cineangiograms filmed in oblique positions. Am J Cardiol 1978;41:726-32.

4 Goris ML, Briandet PA, Huffer E. Automation and operator independent data processing of cardiac and pulmonary functions: role, methods and results. In: Di Paolo R, Kahn E, eds. Information processing in medical imaging. Proceedings of the sixth international conference. Paris: INSERM, 1979;88:427-49.

5 Walton S, Yiannikas J, Jarritt PH, Brown NJG, Swanton RH, Ell PJ. Phasic abnormalities of left ventricular emptying in coronary artery disease. $\mathrm{Br}$ Heart $J$ 1981;46:245-53.

6 Bland JM, Altman DG. Statistical methods for assessing agreement between two methods of clinical measurement. Lancet 1986;i:307-10.

7 Geigel R. Die Klinische Verwertung der Herzsilhouette. $M M W$ 1914;61:1220-1.

8 Chapman CB, Baker O, Reynolds J, Bonte FJ. Use of biplane cinefluorography for measurement of ventricular volume. Circulation 1958;18:1105-17.

9 Arvidsson H. Angiocardiographic determination of left ventricular volume. Acta Radiologica 1961;56:321-9.

10 Dodge HT, Sandler H, Ballew DW, Lord JT Jr. The use of biplane angiocardiography for measurement of left ventricular volume in man. Am Heart J 1960;60:762-76.

11 Sandler H, Dodge HT. The use of single plane angiocardiograms for the calculation of left ventricular volume in man. Am Heart $J$ 1968;75:325-34.
12 Kennedy JW, Trenholme SE, Kasser IS. Left ventricular volume and mass from single-plane cine angiocardiogram. A comparison of anteroposterior and right anterior oblique methods. Am Heart J 1970;80:343-52.

13 Soloff LA. On measuring left ventricular volume. $\mathrm{Am} \mathrm{J}$ Cardiol 1966;18:2-5.

14 Dodge HT, Sandler H, Baxley WA, Hawley RR. Usefulness and limitations of radiographic methods for determining left ventricular volume. Am J Cardiol 1966;18:10-24.

15 Sechtem U, Pflugfelder PW, Gould RG, Cassidy MM, Higgins CB. Measurement of right and left ventricular volumes in healthy individuals with cine $M R$ imaging. Radiology 1987;163:697-702.

16 Utz JA, Herfkens RJ, Heinsimer JA, et al. Cine MR determination of left ventricular ejection fraction. $\mathrm{Am}$ J Roentgenol 1987;148:839-43.

17 Møgelvang J, Thomsen C, Mehlsen J, Bräckle G, Stubgaard $M$, Henriksen $O$. Evaluation of left ventricular volumes measured by magnetic resonance imaging. Eur Heart J 1986;7:1016-21.

18 Markiewicz W, Sechtem U, Kirby R, Derugin N, Caputo GC, Higgins CB. Measurement of ventricular volumes in the dog by nuclear magnetic resonance imaging. J Am Coll Cardiol 1987;10:170-7.

19 Buckwalter KA, Aisen AM, Dilworth LR, Mancini GBJ, Buda AJ. Gated cardiac MRI: ejection fraction determination using the right anterior oblique view. Am J Roentgenol 1986;147:33-7.

20 Just H, Holubarsch C, Friedburg H. Estimation of left ventricular volume and mass by magnetic resonance imaging: comparison with quantitative biplane angiography. Cardiovasc Intervent Radiol 1987;10: $1-4$.

21 Stratemeier EJ, Thompson R, Brady TJ, et al. Ejection fraction determination by $M R$ imaging: comparison with left ventricular angiography. Radiology 1986; 158:775-7.

22 Osbakken M, Yuschok T. Evaluation of ventricular function with gated cardiac magnetic resonance imaging. Cathet Cardiovasc Diagn 1986;12:156-60.

23 Nayler GL, Firmin DN, Longmore DB. Blood flow imaging by cine magnetic resonance. J Comput Assist Tomogr 1986;10:715-22.

24 Underwood SR, Firmin DN, Klipstein RH, Rees RSO, Longmore DB. Magnetic resonance velocity mapping: clinical application of a new technique. $\mathrm{Br}$ Heart $J$ 1987;57:404-12.

25 Underwood SR, Rees RSO, Savage PE, et al. Assessment of regional left ventricular function by magnetic resonance. Br Heart J 1986;56:334-40. 